\title{
shRNA-armed conditionally replicative adenoviruses: promising approach for cancer therapy
}

\author{
Jie Zhang ${ }^{1}$, Meng Ding ${ }^{1}$, Kai Xu' ${ }^{1}$, Lijun Mao ${ }^{1,2}$ and Junian Zheng ${ }^{1}$ \\ 1 Jiangsu Key Laboratory of Biological Cancer Therapy, Xuzhou Medical College, Xuzhou, China \\ ${ }^{2}$ Department of Urinary Surgery, The Affiliated Hospital of Xuzhou Medical College, Xuzhou, China \\ Correspondence to: Lijun Mao, email: maolijunxz@163.com
}

Junian Zheng, email: zhengjunnian@163.com

Keywords: conditionally replicating adenoviruses, RNA interference, cancer, target therapy

Received: December 09, 2015 Accepted: February 15, 2016

Published: March 10, 2016

\section{ABSTRACT}

The small-interfering RNAs (siRNAs) have been employed to knockdown the expression of cancer-associated genes and shown some promise in cancer therapy. However, synthetic siRNA duplexes or plasmid mediated delivery of siRNAs have several problems, such as short half-life, low transfection efficiency and cytotoxicity associated with transfection. Conditionally replicating adenovirus (CRAds) as the delivery vector for short hairpin RNAs (shRNAs) could overcome these limitations and have shown augmented anti-tumor effects in experimental studies and preclinical trials. In this review, we summarize recent progress in the development of CRAdsshRNA for cancer treatment. Combination of CRAds-shRNA with chemotherapeutics, radiation, dendritic cells, monoclonal antibodies and small-molecule inhibitors will be necessary to eradicate cancer cells and cancer stem cells and achieve superior outcomes. The use of CRAd platform for efficient delivery of shRNAs and foreign genes will open a new avenue for cancer therapy.

\section{INTRODUCTION}

RNA interference (RNAi) is a powerful tool for gene knockdown by sequence-specific post-transcriptional targeting [1]. Many studies have indicated the potential of RNAi for the treatment of cancer, especially those caused by abnormal gene expression. However, synthetic smallinterfering RNA (siRNA) duplexes or plasmid mediated delivery of siRNAs bring many challenges, such as short half-life, low transfection efficiency and cytotoxicy associated with transfection [2]. In contrast, the application of RNAi technology in the context of conditionally replicative adenoviruses (CRAds) has various advantages, because CRAds replicate specifically in cancer cells and continuously knockdown the expression of oncogenes (Figure 1).

CRAds are natural or genetically modified viruses that selectively replicate in and kill neoplastic cells while sparing normal cells $[3,4]$. Numerous CRAds have been developed in preclinical models and early clinical trials. Oncolytic Ad5-based viruses demonstrated efficacy and safety in preclinical and clinical trials [5-12]. Phase I human trials with CRAds have confirmed the overall safety of this approach. ONYX-015, an adenovirus, has been tested in randomized trials [13-16]. ONYX-015 was generated by deleting viral E1B 55KD gene, resulting in complete loss of E1B 55KD expression [17]. This modification enabled ONYX-015 to selectively infect and kill p53-deficient cancer cells without damaging normal cells, due to p53-mediated growth arrest [18]. Although ONYX-015 has been used extensively in clinical trials of cancer therapy, the clinical response rates have been suboptimal $[19,20]$. One major obstacle is that ONYX015 is only effective in p53-deficient tumors, and p53 is mutated in approximately $50 \%$ of all human cancers [21]. In addition, the deletion of E1B 55KD reduces the replication and production of Ads, resulting in reduced anti-tumor efficacy of CRAds.

To enhance the specificity and efficacy of CRAds for cancer treatment, oncolytic viruses have been modified to combine oncolytic replication with therapeutic transgenic expression. In this review we summarize recent progress in the utilization of CRAd-shRNA in cancer therapy and discuss novel strategies to develop highly efficient oncolytic Ads. 


\section{STRATEGIES TO DEVELOP ONCOLYTIC ADENOVIRUS MEDIATED SHRNA}

Most adenoviral vectors used in RNAi delivery are derived from human serotypes 2 and 5. Carette et al. were the first to propose using shRNA with oncolytic viruses in cancer gene therapy [22]. This system can generate a two-pronged attack on tumor cells through oncogene knockdown and viral oncolysis. Up to now, the use of an oncolytic adenovirus platform for shRNA delivery can be divided into four forms (Figure 2).

\section{Oncolytic adenoviruses armed with one shRNA}

The first strategy of oncolytic viruses armed RNAi involves the use of one shRNA. In the prototype, Carette et al. constructed CRAds encoding shRNAs against firefly luciferase and demonstrated that siRNAs expressed from CRAds could suppress the expression of firefly luciferase. In particular, the efficiency of silencing increased during viral replication [22]. Zhang et al. were the first to use oncolytic viral-transgene platform to achieve siRNAmediated gene silencing that led to tumor cell death [23]. In recent years, our group has extensively tested this strategy using ZD55 which is defective in E1B gene. We have constructed ZD55-shRNAs against the genes overexpressed in cancer cells and examined the anticancer efficacy of recombinant ZD55-shRNAs such as ZD55-Ki67, ZD55-hTERT and ZD55-shMYCN [24-26]. We expanded this strategy to construct ZD55-SATB1, an oncolytic adenovirus carrying shRNA targeting SATB1, a oncogenic transcription factor [27]. We found that ZD55SATB1 selectively replicated and significantly reduced SATB1 expression in DU145 and LNCaP cells. ZD55SATB1 effectively inhibited the viability and invasion of DU145 and LNCaP cells in vitro and inhibited prostate cancer growth and metastasis in xenograft nude mice [27]. Our results indicate that the combination of oncolytic virotherapy and shRNA enhances the anti-tumor potency.

Yun et al. developed an E1A/E1B double mutant replicating adenovirus Ad- $\Delta \mathrm{E} 1 \mathrm{Bmt} 7$ [28], and constructed a series of Ad- $\triangle \mathrm{E} 1 \mathrm{Bmt} 7$ armed with shRNAs targeting the key mediators in angiogenesis, the armed Ad-

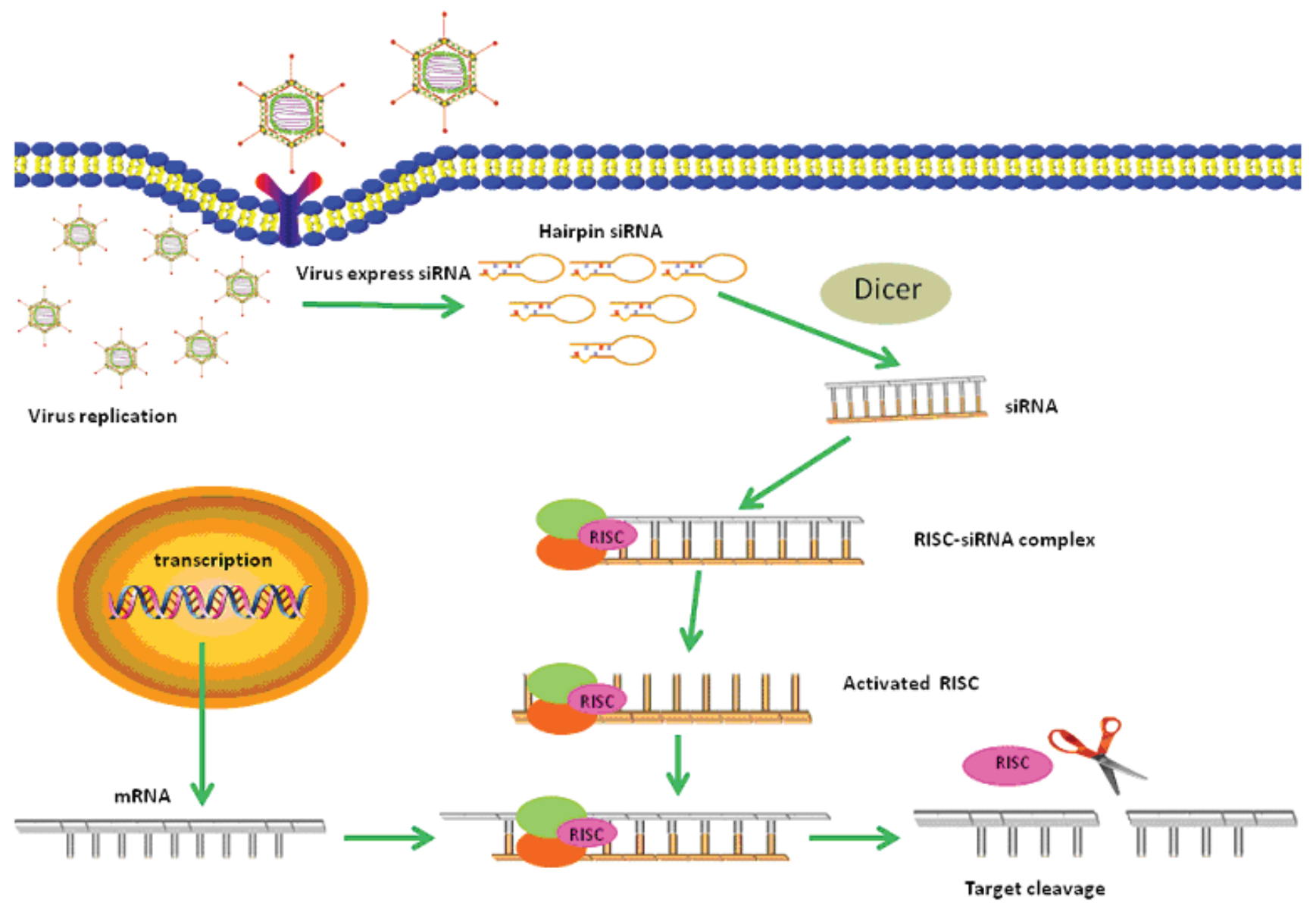

Figure 1: A schematic diagram of anti-tumor effects of CRAd-shRNA based therapy. After CRAds infect and replicate in tumor cells, shRNAs are expressed within the nucleus where they spontaneously form hairpin RNAs and are transported to the cytoplasm. Then shRNAs are cleaved by Dicer into active siRNAs. Binding of the siRNA to RISC results in the activation of this complex, and after subsequent duplex unwinding, RISC facilitates the binding of target homologous mRNAs. Perfect binding sequences result in the cleavage and silencing of target genes. 
$\triangle \mathrm{E} 1 \mathrm{Bmt} 7$ demonstrated greater anti-tumor and antiangiogenesis efficacy than Ad- $\Delta \mathrm{E} 1 \mathrm{Bmt} 7$ alone, when injected intratumorally in subcutaneous models of glioma, hepatocellular carcinoma and lung carcinoma [29-31]. Recently, Chen and colleagues employed adenovirusmediated siRNA to knockdown FAT10 expression in hepatocellular carcinoma cells. These replicating viruses specifically silenced target gene and potently inhibited tumor growth in vivo [32].

\section{Oncolytic adenoviruses armed with dual or multiple shRNAs}

The second strategy involves the use of dual or multiple shRNAs in one Ad vector. Jazag et al. were the first to establish the method for simultaneous silencing of multiple targets by shRNA-expressing RNAi plasmid vectors [33]. The multi-siRNA engineering technology has been applied in the construction of adenoviral vectors [34]. Motegi et al. developed an efficient Ad vector-mediated RNAi system carrying four shRNA-expression cassettes [35]. Ad-multi-shRNA vectors showed enhanced gene silencing compared to conventional Ad vectors containing a single shRNA-expression cassette. Our team tested a 'dual target' approach by constructing double siRNAs (targeting Ki67 and hTERT) delivered by one oncolytic adenovirus [36]. The double siRNAs armed oncolytic adenoviruses could kill renal cancer cells effectively. Another recent study reported that single promoterdriven multi-cistronic shRNAs for XIAP, Akt and Bcl-2 effectively silenced multiple target genes [37].

We postulate that simultaneous targeting of two or multiple tumor-specific genes using oncolytic adenovirus and siRNA enhances therapeutic efficacy against tumors, but could augment the inherent risks, including immune responses, cytotoxicity, off-targeting and oversaturation of endogenous pathways. Moreover, the optimization of siRNA is needed for stable knockdown of multiple genes. These factors should be taken into account when combinatorial RNAi is selected for gene therapy.

\section{Oncolytic adenoviruses armed with shRNA and therapeutic genes}

Recently, cancer gene therapy has focused on utilizing cytokines, tumor suppressor, and apoptosis

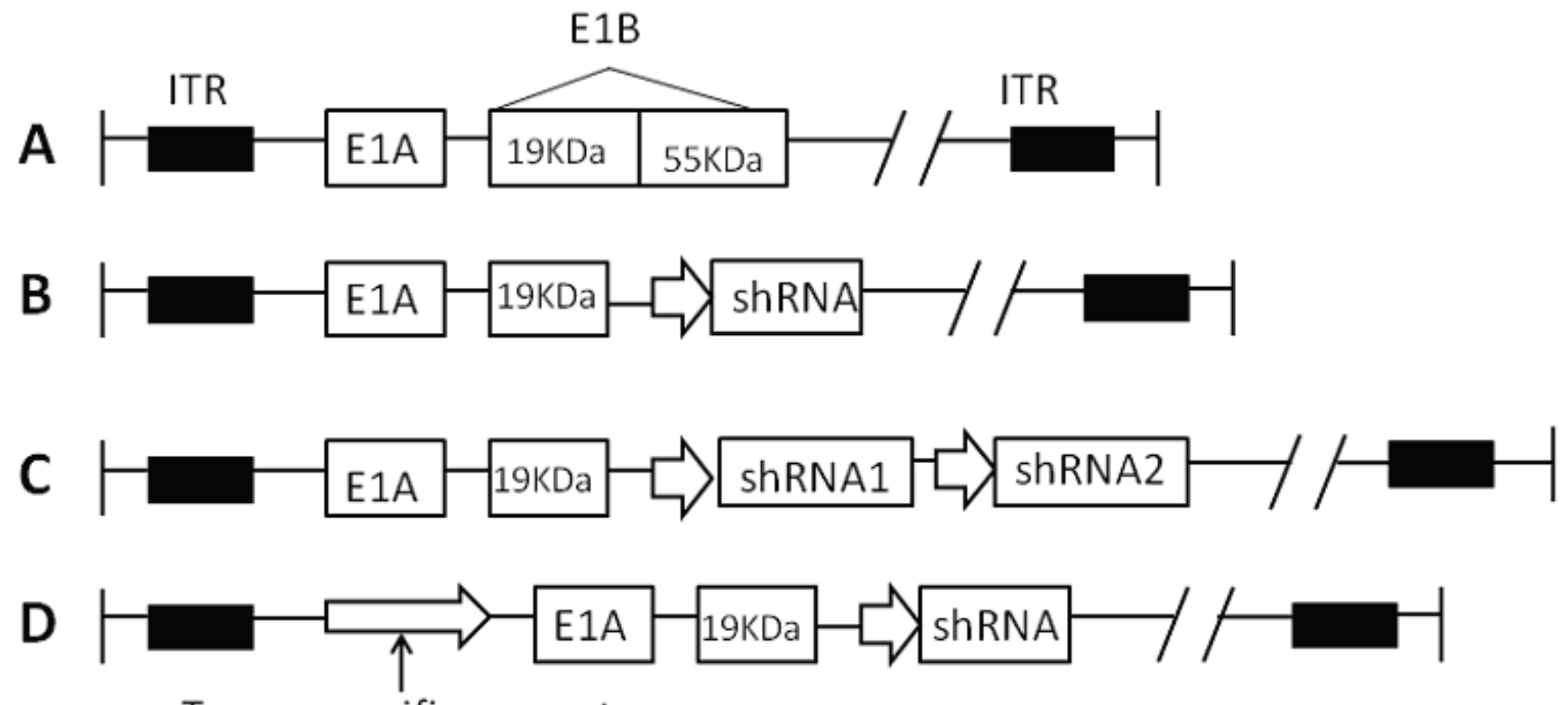

Tumor specific promoter

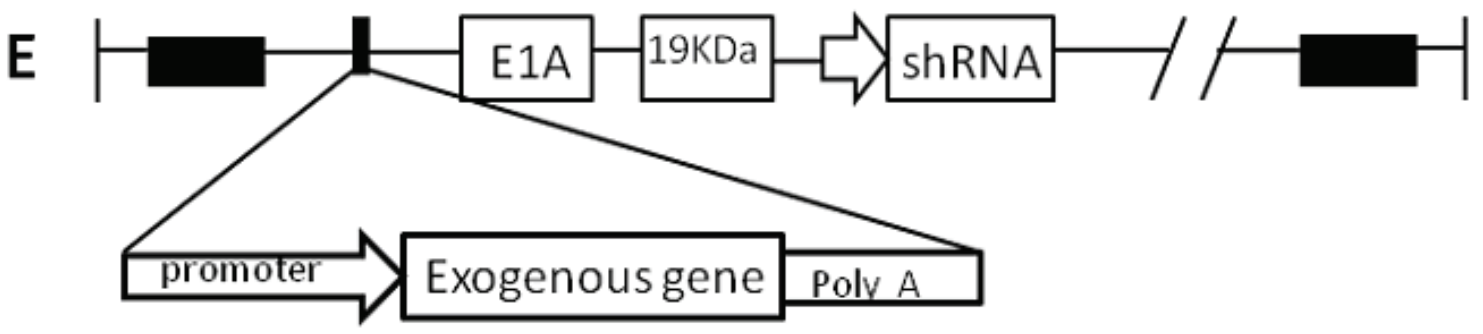

Figure 2: The schematic stucture of CRAd vector for shRNA. A. Wild type adenovirus. B. In recombinant adenovirus, E1B55KD gene was replaced by one shRNA sequence expression cassette. C. CRAd vector harboring double-cistronic shRNA expression construct. D. CRAd armed with shRNA and tumor specific promoter. E. CRAd armed with shRNA and exogenous therapeutic genes. 
Table 1: Typical examples of CRAds armed with shRNA

\begin{tabular}{|c|c|c|c|c|}
\hline Function of targets & Cancer types & Effects & $\begin{array}{l}\text { Genes } \\
\text { targeted } \\
\end{array}$ & References \\
\hline Regulation of cell cycle & Renal carcinoma & Antitumor & Ki67 & {$[27]$} \\
\hline proto-oncogenes & Neuroblastoma & Antitumor & MYCN & {$[29]$} \\
\hline Transcription factor & Prostate cancer & Antitumor & SATB1 & {$[30]$} \\
\hline Pro-angiogenic factor & $\begin{array}{l}\text { Glioma, hepatocellular } \\
\text { carcinoma (HCC) }\end{array}$ & Antitumor & VEGF & {$[32-34]$} \\
\hline Ubiquitin-related family & $\mathrm{HCC}$ & Antitumor & FAT10 & {$[35]$} \\
\hline tumor growth and metastasis & $\mathrm{HCC}$ & Antitumor & FAK & {$[58]$} \\
\hline $\begin{array}{l}\text { Cell immortalization and } \\
\text { tumorigenesis }\end{array}$ & $\begin{array}{l}\text { Cervical cancer, renal } \\
\text { carcinoma, fibrosarcoma }\end{array}$ & Antitumor & hTERT & {$[28],[41]$} \\
\hline $\begin{array}{l}\text { tumor growth, invasion, and } \\
\text { metastasis }\end{array}$ & $\begin{array}{l}\text { prostate cancer, gastric } \\
\text { carcinoma, breast cancer }\end{array}$ & Antitumor & EphA3 & {$[56]$} \\
\hline \multirow[t]{3}{*}{$\begin{array}{l}\text { Inhibitor of apoptotic } \\
\text { protein }\end{array}$} & $\begin{array}{l}\text { Colon cancer, renal } \\
\text { carcinoma }\end{array}$ & $\begin{array}{l}\text { Silence target } \\
\text { gene }\end{array}$ & $\begin{array}{l}\text { XIAP, } \quad \text { Bcl- } \\
\text { 2,Akt }\end{array}$ & {$[42],[45]$} \\
\hline & $\begin{array}{l}\text { Cervical cancer, } \\
\text { adenocarcinoma, } \\
\text { fibrosarcoma }\end{array}$ & $\begin{array}{l}\text { Enhance } \\
\text { chemotherapy } \\
\text { efficacy }\end{array}$ & Apollon & {$[76]$} \\
\hline & Colorectal cancer & $\begin{array}{l}\text { Enhance } \\
\text { chemotherapy } \\
\text { efficacy }\end{array}$ & Survivin & {$[72]$} \\
\hline $\begin{array}{l}\text { DNA double strand break } \\
\text { repair }\end{array}$ & Colon cancer & $\begin{array}{l}\text { Enhance } \\
\text { radiotherapy } \\
\text { efficacy }\end{array}$ & DNA-PKCs & {$[82]$} \\
\hline
\end{tabular}

related genes as therapeutic genes [38, 39]. CRAds armed with a variety of transgenes enhance the killing of cancer cells, modulate tumor microenvironment, and stimulate immune response to the tumor. Replicating oncolytic Ads are able to infect and deliver therapeutic genes to adjacent cells in addition to those infected initially. Furthermore, CRAds induce high expression of therapeutic genes through increased adenoviral replication, and restrict the expression of therapeutic genes to cancer cells. Central to this strategy, however, is the engineering of Ads vectors that can efficiently deliver therapeutic genes of interest and siRNAs targeting oncogenes together to solid tumors. Pan et al. utilized ZD55 to deliver X-linked inhibitor-of-apoptosis protein (XIAP) shRNA and TRAIL into hepatocellular carcinoma cells and demonstrated significant reduction of XIAP expression and potent anti-tumor activity both in hepatocellular carcinoma cells and in tumor animal model. However, the effect in vivo was not as adequate as that of in vitro experiments, particularly at late stage [40]. The phenomena may suggest that conventional oncolytic adenoviral vectors are not so efficient for long-term siRNA delivery, probably 
due to the elimination of oncolytic adenovirus by host or the expression of noncoding adenovirus VA RNAI and VA RNAII that have the capacity to suppress RNAi at late stage of infection [41]. Therefore, these oncolytic adenoviruses need to be further modified, such as deleting VA RNAI and VA RNAII, to provide a more efficient oncolytic vehicle for siRNA delivery in cancer therapy.

\section{Oncolytic adenoviruses armed with shRNA and tumor specific promoter}

The nonspecific native tropism of the adenovirus limits the efforts to target cancer cells specifically, and increases the potential for side effects. One strategy is the use of tumor-specific promoters (TSPs) to selectively drive viral E1 expression to increase tumor specificity. This is typically accomplished by placing viral E1A gene under the control of an exogenous promoter that is active or induced in the particular cancer that is being targeted. The most commonly used promoter that augments virus specificity is hTERT, which is active in $85-90 \%$ of tumor tissues and is detectable in the early stages of malignancy [42]. hTERT promoter is inactive in most normal host tissues but displays high activity in a majority of human cancers $[43,44]$. Telomerase is thus considered as an ideal tumor-specific regulator of oncolytic adenoviruses [45]. Zhao et al. tested this approach by combining Ad-TERTp with siRNA targeting EphA3, a potential oncogene. They found that Ad-TERTp-E1A-EphA3 shRNA had 3.5and 1,400- fold greater ability to kill EphA3 and TERT expressing tumor cells compared to Ad-TERTp-E1A$\mathrm{NC}$ and Ad- $\triangle \mathrm{E} 1 \mathrm{~A}-\mathrm{EphA} 3$ shRNA, respectively, while had little effect on cells that modestly expressed EphA3 and TERT. The anti-tumor efficacy of Ad-TERTp-E1AEphA3 shRNA was further validated in vivo [46].

We constructed oncolytic virus G250-Ki67, and G250 promoter-derived CRAds carrying Ki67-siRNA could efficiently amplify and deliver Ki67-siRNA in renal cancer cells, leading to inhibited proliferation and enhanced apoptosis [47]. A recent study reported the engineering of adenovirus Ad-hTERT-HREAF (named SG505). shRNA against focal adhesion kinase (FAK) was inserted into SG505 to form Ad-hTERT-HREAF-shRNA (called SG505-siFAK). Both replicative and replicationdefective adenoviruses carrying FAK-shRNA significantly inhibited FAK expression and efficiently suppressed the growth of liver cancer cells with minor effect to normal cells [48].

\section{CRADSBASED COMBINATIONTHERAPY}

The monotherapy of adenovirus has demonstrated limited efficacy in a clinical setting [49]. Comprehensive therapy has become dominant feature in improving tumor therapy [50-52]. Therefore, oncolytic adenoviruses have been used in combination with other tumor treatment strategies, including gene therapy, cell therapy, and traditional radiation and chemotherapy [53-56].

\section{CRAds in combination with chemotherapy}

Preclinical and clinical trials support that CRAds gene therapy and chemotherapy have complementary or synergistic effects, leading to better anti-tumor effect than either treatment alone. One effective approach in the treatment of malignant tumors is direct injection of CRAds combined with chemotherapeutic agents. Another means of combined therapy is the use of CRAd-shRNA to knockdown genes associated with chemoresistance in tumor cells.

Apollon is a membrane-associated inhibitor of apoptosis and is upregulated in chemoresistant cancer cells [57]. Chu et al. constructed ZD55-siApollon to knockdown Apollon and showed that ZD55-siApollon inhibited tumor progression in vivo, but the tumors were not eliminated. In contrast, complete tumor eradication was observed when tumors were co-injected with ZD55siApollon and 5-FU [58]. Another recombinant adenovirus armed with shRNA targeting surviving was administrated together with 5-FU and inhibited cancer metastasis both in vitro and in vivo [59].

\section{CRAds in combination with radiotherapy}

Total radiation dose that can be delivered to cancer is limited by the damage to normal tissues that are irradiated during radiotherapy [60]. Recently, several studies have shown that the combination of radiotherapy and oncolytic adenovirus mediated gene therapy has synergistic suppressive effects on the growth of various cancer cells [61-63]. Notably, a prospective randomized phase 2 trial showed that combining oncolytic adenovirus mediated cytotoxic gene therapy with radiation therapy did not exacerbate the most common side effects of prostate radiation therapy [64].

Takashi et al. engineered a replication-deficient adenovirus encoding shRNA targeting DNA-PKcs to treat human HCT116 colon cancer cells, leading to increased radiation sensitivity [65]. When CRAds targeted to telomerase-positive tumor cells was used in conjunction with non-replicative adenovirus harboring DNA-PKcsshRNA, the efficiency of tumor-specific knockdown of DNA-PKcs was enhanced significantly, contributing to significant anti-tumor efficacy of concurrent radiation therapy. These results suggest that shRNA mediated DNA-PKcs knockdown in combination with replicative adenovirus is a promising approach for the sensitization of solid tumors to radiation therapy. 


\section{CRAds in combination with immunotherapy}

For cancer immunotherapy, different kinds of immune cells have been used including dendritic cells (DCs), cytokine-induced killer (CIK) cells, cytotoxic T lymphocytes (CTLs) and natural killer (NK) cells [66-70]. DCs are highly efficient and specialized antigen-presenting cells. However, tumor tissues produce immunosuppressive molecules such as vascular endothelial growth factor (VEGF) and transforming growth factor $\beta$ to induce an immunosuppressive microenvironment and inhibit the function of tumor-associated DCs [71]. To augment the anti-tumor efficiency of cytokine-mediated immunotherapy, Huang et al. administered IL-12 and 4-1BBL co-expressing oncolytic adenovirus with DCs [72]. The combination of CRAds and DCs elicited greater anti-tumor and anti-metastatic effects than either treatment alone. The enhanced anti-tumor immune response seems to be mediated by enhanced cytolytic activity of CTLs and IFN- $\gamma$ releasing immune cells [72].

$\mathrm{pRb} / \mathrm{E} 2 \mathrm{~F}$ pathway is abnormal in many solid tumors [73]. Yang et al. used an E2F-1 targeted oncolytic adenovirus in combination with CIK cells for colorectal cancer therapy, and observed strong anti-tumor effect [74]. Later, they inserted IL-15 gene into the E3 region of the adenovirus and found that human IL-15 expressing oncolytic adenovirus (Ad-E2F/IL15) showed stronger anti-tumor effect than simple oncolytic viruses (AdE2F). In addition, the therapeutic effect of Ad-E2F/IL15 in combination with CTLs was clearly stronger than that of single application of oncolytic viruses or CTL [75]. In conclusion, the combination of CRAds and adoptive immune cells can achieve synergistic efficacy for tumor therapy.

\section{CRADS OVERCOME THE CHALLENGES OF CURRENT CANCER THERAPY}

Despite the advantages of CRAds for cancer therapy, two important issues remain as the big challenges. First, cancer stem cells (CSCs) are thought to account for tumor relapses. Second, clinical trials using advanced anticancer therapies fail to reach the outcomes of preclinical studies due to limited distribution throughout solid tumors and quick degradation of the therapeutic payload [76]. Therefore, it is worthwhile to optimize the strategy of siRNA armed CRAds to improve cancer therapy.

\section{CRAds for killing cancer stem cells}

Pierce speculated that tumors contain a small number of malignant stem cells that maintain stem cell function and give rise to progenitor cells with various degree of differentiation [77]. Currently, CSCs have been isolated from the brain, pancreas, ovarian, colorectal, lung, head and neck, breast, liver and a variety of pediatric cancers [78-82]. The stem cell-like properties of CSCs confer resistance to traditional chemotherapy and radiotherapy [82].

A number of studies have explored the use of oncolytic Ads for CSCs targeting. Ad5/3- $\Delta 24$ and Ad5. pK7- $\Delta 24$ had a 24 -base pair deletion in the viral E1A gene, which disrupted the Rb-binding capacity of E1A protein and thereby conferred conditional replication only in cells deficient in Rb/p16 pathway [83, 84]. The RGD peptide allowed the virus to bind and enter the cell through cell surface integrins $\alpha v \beta 3 / 5$, and effectively kill breast cancer cells [85]. Eriksson et al. evaluated the oncolytic potency of CRAds for $\mathrm{CD} 44^{+} \mathrm{CD} 24^{\text {low } /}-$ breast cancer CSCs in vitro and in vivo [86]. When $\mathrm{CD} 44^{+} \mathrm{CD} 24^{\text {low } /}$ cells were injected into the fat pads of SCID mice, tumors formed rapidly, but $\mathrm{CD} 44^{+} / \mathrm{CD} 24^{- \text {/low }}$ cells infected with Ad5/3- $\Delta 24$ showed slower tumor formation [86].

Oncolytic adenovirus Delta24-RGD represents a promising therapeutic agent for malignant glioma. Delta24-RGD showed efficacy against glioma in vitro and in vivo [87], and phase I clinical trial has been recently completed [88]. Histone deacetylase inhibitors (HDACi) are novel anti-cancer drugs and the combination of HDACi and Delta24-RGD showed synergistic anti-tumor activity in patient-derived glioblastoma stem-like cells (GSCs). Meanwhile, the limited toxicity of HDACi to normal human astrocytes makes these drugs interesting candidates for combination with Delta24-RGD for cancer therapy [89].

Moreover, transcriptional targeting mediated by adenoviral vectors using promoters active in CSCs may be a powerful approach for the eradication of CSCs [90]. With the progress made in CSCs biology, next-generation viruses can be developed that target specific CSCs antigens and signaling pathways that promote tumorigenesis.

\section{MSCs mediated systemic delivery of CRAds}

The systemic administration of oncolytic virus is often inefficient, because the virus is susceptible to neutralization by blood components, especially antibodies, and sequestration to healthy organs [91]. An alternative strategy for in vivo delivery of oncolytic viruses is using cell carriers that chaperone viral delivery to the tumor nodules. Carrier cells for oncolytic virus delivery could shield the virus from host defenses and direct them toward tumors. Mesenchymal stromal cells (MSCs) are interesting candidates as carrier cells, because they are easily obtained, cultivated and propagated in vitro, and can home to tumor microenvironments [92]. Using MSCs as a delivery system could improve the distribution of CRAds into tumor, minimize the off-target toxicity and enhance therapy efficacy.

MSCs have been employed to deliver oncolytic virus which subsequently infect and replicate within 
malignant cells and eradicate the tumors [93-97]. When Ad5-Delta24-RGD loaded into MSCs was administered to mice with intracranial glioma, there was $80 \%$ increase in median survival (42 days in controls compared to 75.5 days in treated animals) [97]. Delivery of CRAd by human MSCs was 46-fold more efficient than the injection of CRAd alone, indicating that human MSCs migrate and deliver CRAd to distant glioma cells [95]. It was demonstrated that engineering post-entry steps of oncolytic virus replication could dramatically increase virus dose released by MSCs [98]. The Ad5/3 chimeric OAd capsid increased the entry into human bone marrowderived MSCs and primary pancreatic cancer cells. The combination of MSCs mediated virus delivery with 5-FC/5-FU prodrug activation showed very strong tumor cell killing ability [98].

\section{CONCLUDING REMARKS}

CRAds can be used as gene delivery vehicles to tumors, in addition they independently induce oncolysis and avoid the damage of adjacent normal cells. A variety of strategies have been designed to enhance the oncolytic effects of CRAds. Among them, two major strategies of CRAds armed with shRNA have been pursued: i) improve the efficiency and selectivity by silencing multiple target genes, co-expression of tumor suppressor genes or using tumor specific promoters; ii) improve CRAds delivery and reduce virus clearance by using MSCs as cell delivery vehicles. Combination therapy with chemotherapeutics, radiation, dendritic cells, monoclonal antibodies, smallmolecule inhibitors will be necessary to eliminate cancer cells and CSCs to achieve superior outcomes. The use of CRAd platform for shRNA and transgenic delivery will open a new avenue for cancer therapy.

\section{ACKNOWLEDGMENTS}

We thank Prof. CHU Liang (Laboratory of Molecular Cell Biology, Institute of Biochemistry and Cell Biology, Shanghai Institutes for Biological Sciences, Chinese Academy of Sciences, Shanghai, China) for suggestion.

\section{FUNDING}

This study was supported by grant from National Natural Science Foundation of China (No. 3070099) and Natural Science Foundation of Jiangsu Province (No. BK20151166).

\section{CONFLICTS OF INTEREST}

The authors declare no conflicts of interest.

\section{REFERENCES}

1. Haussecker D, Kay MA. RNA interference. Drugging RNAi. Science. 2015; 347:1069-1070.

2. Behlke MA. Progress towards in vivo use of siRNAs. Mol Ther. 2006; 13:644-670.

3. Parato KA, Senger D, Forsyth PAJ, Bell JC. Recent progress in the battle between oncolytic viruses and tumours. Nature Reviews Cancer. 2005; 5:965-976.

4. Hanahan D, Weinberg RA. Hallmarks of cancer: the next generation. Cell. 2011; 144:646-674.

5. Rajecki M, Kanerva A, Stenman UH, Tenhunen M, Kangasniemi L, Sarkioja M, Ala-Opas MY, Alfthan H, Sankila A, Rintala E, Desmond RA, Hakkarainen T, Hemminki A. Treatment of prostate cancer with Ad5/3Delta24hCG allows non-invasive detection of the magnitude and persistence of virus replication in vivo. Mol Cancer Ther. 2007; 6:742-751.

6. Lei J, Li QH, Yang JL, Liu F, Wang L, Xu WM, Zhao WX. The antitumor effects of oncolytic adenovirus H101 against lung cancer. Int J Oncol. 2015; 47:555-562.

7. Freytag SO, Movsas B, Aref I, Stricker H, Peabody J, Pegg J, Zhang Y, Barton KN, Brown SL, Lu M, Savera A, Kim JH. Phase I trial of replication-competent adenovirusmediated suicide gene therapy combined with IMRT for prostate cancer. Mol Ther. 2007; 15:1016-1023.

8. Li JL, Liu HL, Zhang XR, Xu JP, Hu WK, Liang M, Chen SY, Hu F, Chu DT. A phase I trial of intratumoral administration of recombinant oncolytic adenovirus overexpressing HSP70 in advanced solid tumor patients. Gene Ther. 2009; 16:376-382.

9. Nemunaitis J, Tong AW, Nemunaitis M, Senzer N, Phadke AP, Bedell C, Adams N, Zhang YA, Maples PB, Chen S, Pappen B, Burke J, Ichimaru D, Urata Y, Fujiwara T. A Phase I Study of Telomerase-specific Replication Competent Oncolytic Adenovirus (Telomelysin) for Various Solid Tumors. Molecular Therapy. 2010; 18:429434.

10. Yang SW, Cody JJ, Rivera AA, Waehler R, Wang M, Kimball KJ, Alvarez RA, Siegal GP, Douglas JT, Ponnazhagan S. Conditionally replicating adenovirus expressing TIMP2 for ovarian cancer therapy. Clin Cancer Res. 2011; 17:538-549.

11. Freytag SO, Stricker H, Lu M, Elshaikh M, Aref I, Pradhan D, Levin K, Kim JH, Peabody J, Siddiqui F, Barton K, Pegg J, Zhang Y, Cheng J, Oja-Tebbe N, Bourgeois R, Gupta N, Lane Z, Rodriguez R, DeWeese T, Movsas B. Prospective randomized phase 2 trial of intensity modulated radiation therapy with or without oncolytic adenovirus-mediated cytotoxic gene therapy in intermediate-risk prostate cancer. Int J Radiat Oncol Biol Phys. 2014; 89:268-276.

12. Kanerva A, Nokisalmi P, Diaconu I, Koski A, Cerullo V, Liikanen I, Tahtinen S, Oksanen M, Heiskanen R, Pesonen S, Joensuu T, Alanko T, Partanen K, Laasonen L, Kairemo 
K, Pesonen S, Kangasniemi L, Hemminki A. Antiviral and antitumor T-cell immunity in patients treated with GMCSF-coding oncolytic adenovirus. Clin Cancer Res. 2013; 19:2734-2744.

13. Kirn D, Hermiston T, McCormick F. ONYX-015: Clinical data are encouraging. Nature Medicine. 1998; 4:1341-1342.

14. Makower D, Rozenblit A, Kaufman H, Edelman M, Lane ME, Zwiebel J, Haynes H, Wadler S. Phase II clinical trial of intralesional administration of the oncolytic adenovirus ONYX-015 in patients with hepatobiliary tumors with correlative p53 studies. Clin Cancer Res. 2003; 9:693-702.

15. Rudin CM, Cohen EE, Papadimitrakopoulou VA, Silverman S, Jr., Recant W, El-Naggar AK, Stenson K, Lippman SM, Hong WK, Vokes EE. An attenuated adenovirus, ONYX015 , as mouthwash therapy for premalignant oral dysplasia. J Clin Oncol. 2003; 21:4546-4552.

16. Morley S, MacDonald G, Kirn D, Kaye S, Brown R, Soutar D. The d11520 virus is found preferentially in tumor tissue after direct intratumoral injection in oral carcinoma. Clin Cancer Res. 2004; 10:4357-4362.

17. Khuri FR, Nemunaitis J, Ganly I, Arseneau J, Tannock IF, Romel L, Gore M, Ironside J, MacDougall RH, Heise C, Randlev B, Gillenwater AM, Bruso P, Kaye SB, Hong WK, Kirn DH. a controlled trial of intratumoral ONYX-015, a selectively-replicating adenovirus, in combination with cisplatin and 5-fluorouracil in patients with recurrent head and neck cancer. Nat Med. 2000; 6:879-885.

18. Bischoff JR, Kim DH, Williams A, Heise C, Horn S, Muna M, Ng L, Nye JA, SampsonJohannes A, Fattaey A, McCormick F. An adenovirus mutant that replicates selectively in p53-deficient human tumor cells. Science. 1996; 274:373-376.

19. Kirn D. Clinical research results with d11520 (Onyx-015), a replication-selective adenovirus for the treatment of cancer: what have we learned? Gene Ther. 2001; 8:89-98.

20. Kirn D. Oncolytic virotherapy for cancer with the adenovirus d11520 (Onyx-015): results of phase I and II trials. Expert Opin Biol Ther. 2001; 1:525-538.

21. Bergh J, Norberg T, Sjogren S, Lindgren A, Holmberg L. Complete Sequencing of the P53 Gene Provides Prognostic Information in Breast-Cancer Patients, Particularly in Relation to Adjuvant Systemic Therapy and Radiotherapy. Nature Medicine. 1995; 1:1029-1034.

22. Carette JE, Overmeer RM, Schagen FH, Alemany R, Barski OA, Gerritsen WR, Van Beusechem VW. Conditionally replicating adenoviruses expressing short hairpin RNAs silence the expression of a target gene in cancer cells. Cancer Res. 2004; 64:2663-2667.

23. Zhang YA, Nemunaitis J, Samuel SK, Chen P, Shen Y, Tong AW. Antitumor activity of an oncolytic adenovirusdelivered oncogene small interfering RNA. Cancer Res. 2006; 66:9736-9743.

24. Zheng JN, Pei DS, Mao LJ, Liu XY, Mei DD, Zhang BF, Shi Z, Wen RM, Sun XQ. Inhibition of renal cancer cell growth in vitro and in vivo with oncolytic adenovirus armed short hairpin RNA targeting Ki-67 encoding mRNA. Cancer Gene Ther. 2009; 16:20-32.

25. Zheng JN, Pei DS, Sun FH, Zhang BF, Liu XY, Gu JF, Liu YH, Hu XL, Mao LJ, Wen RM, Liu JJ, Li W. Inhibition of renal cancer cell growth by oncolytic adenovirus armed short hairpin RNA targeting hTERT gene. Cancer Biol Ther. 2009; 8:84-91.

26. Li Y, Zhang B, Zhang H, Zhu X, Feng D, Zhang D, Zhuo B, Li L, Zheng J. Oncolytic adenovirus armed with shRNA targeting MYCN gene inhibits neuroblastoma cell proliferation and in vivo xenograft tumor growth. J Cancer Res Clin Oncol. 2013; 139:933-941.

27. Mao LJ, Zhang J, Liu N, Fan L, Yang DR, Xue BX, Shan YX, Zheng JN. Oncolytic virus carrying shRNA targeting SATB1 inhibits prostate cancer growth and metastasis. Tumour Biol. 2015.

28. Kim J, Kim JH, Choi KJ, Kim PH, Yun CO. E1A- and E1B-Double mutant replicating adenovirus elicits enhanced oncolytic and antitumor effects. Hum Gene Ther. 2007; 18:773-786.

29. Yoo JY, Kim JH, Kwon YG, Kim EC, Kim NK, Choi HJ, Yun CO. VEGF-specific short hairpin RNAexpressing oncolytic adenovirus elicits potent inhibition of angiogenesis and tumor growth. Mol Ther. 2007; 15:295302.

30. Yoo JY, Kim JH, Kim J, Huang JH, Zhang SN, Kang YA, Kim H, Yun CO. Short hairpin RNA-expressing oncolytic adenovirus-mediated inhibition of IL-8: effects on antiangiogenesis and tumor growth inhibition. Gene Ther. 2008; 15:635-651.

31. Kang YA, Shin HC, Yoo JY, Kim JH, Kim JS, Yun CO. Novel cancer antiangiotherapy using the VEGF promotertargeted artificial zinc-finger protein and oncolytic adenovirus. Mol Ther. 2008; 16:1033-1040.

32. Chen J, Yang L, Chen H, Yuan T, Liu M, Chen P. Recombinant adenovirus encoding FAT10 small interfering RNA inhibits HCC growth in vitro and in vivo. Exp Mol Pathol. 2014; 96:207-211.

33. Jazag A, Kanai F, Ijichi H, Tateishi K, Ikenoue T, Tanaka Y, Ohta M, Imamura J, Guleng B, Asaoka Y, Kawabe T, Miyagishi M, Taira K, Omata M. Single small-interfering RNA expression vector for silencing multiple transforming growth factor-beta pathway components. Nucleic Acids Res. 2005; 33:e131.

34. Li X, Liu S, Wang D, Chen H, Xia H. Adenoviral delivered eGFP-intron splicing system for multiple gene RNAi. Biotechnol Lett. 2011; 33:1723-1728.

35. Motegi Y, Katayama K, Sakurai F, Kato T, Yamaguchi T, Matsui H, Takahashi M, Kawabata K, Mizuguchi H. An effective gene-knockdown using multiple shRNAexpressing adenovirus vectors. J Control Release. 2011; 153:149-153.

36. Fang L, Cheng Q, Li W, Liu J, Li L, Xu K, Zheng J. 
Antitumor activities of an oncolytic adenovirus equipped with a double siRNA targeting Ki67 and hTERT in renal cancer cells. Virus Res. 2014; 181:61-71.

37. Junn HJ, Kim JY, Seol DW. Effective knockdown of multiple target genes by expressing the single transcript harbouring multi-cistronic shRNAs. Biochem Biophys Res Commun. 2010; 396:861-865.

38. Wadhwa PD, Zielske SP, Roth JC, Ballas CB, Bowman JE, Gerson SL. Cancer gene therapy: scientific basis. Annu Rev Med. 2002; 53:437-452.

39. Podhajcer OL, Lopez MV, Mazzolini G. Cytokine gene transfer for cancer therapy. Cytokine Growth Factor Rev. 2007; 18:183-194.

40. Pan Q, Liu B, Liu J, Cai R, Liu X, Qian C. Synergistic antitumor activity of XIAP-shRNA and TRAIL expressed by oncolytic adenoviruses in experimental HCC. Acta Oncol. 2008; 47:135-144.

41. Andersson MG, Haasnoot PC, Xu N, Berenjian S, Berkhout B, Akusjarvi G. Suppression of RNA interference by adenovirus virus-associated RNA. J Virol. 2005; 79:95569565.

42. Shay JW, Bacchetti S. A survey of telomerase activity in human cancer. Eur J Cancer. 1997; 33:787-791.

43. Kim NW, Piatyszek MA, Prowse KR, Harley CB, West MD, Ho PL, Coviello GM, Wright WE, Weinrich SL, Shay JW. Specific association of human telomerase activity with immortal cells and cancer. Science. 1994; 266:2011-2015.

44. Mo Y, Gan Y, Song S, Johnston J, Xiao X, Wientjes MG, $\mathrm{Au}$ JL. Simultaneous targeting of telomeres and telomerase as a cancer therapeutic approach. Cancer Res. 2003; 63:579585.

45. Doloff JC, Waxman DJ, Jounaidi Y. Human telomerase reverse transcriptase promoter-driven oncolytic adenovirus with E1B-19 kDa and E1B-55 kDa gene deletions. Hum Gene Ther. 2008; 19:1383-1400.

46. Zhao Y, Li H, Wu R, Li S, Wang P, Wang H, Wang J, Zhou J. Antitumor Effects of Oncolytic Adenovirus-Carrying siRNA Targeting Potential Oncogene EphA3. PLoS One. 2015; 10:e126726.

47. Liu J, Fang L, Cheng Q, Li L, Su C, Zhang B, Pei D, Yang J, Li W, Zheng J. Effects of G250 promoter controlled conditionally replicative adenovirus expressing Ki67siRNA on renal cancer cell. Cancer Sci. 2012; 103:18801888.

48. Gao Y, Zhu Y, Huang X, Ai K, Zheng Q, Yuan Z. Gene therapy targeting hepatocellular carcinoma by a dualregulated oncolytic adenovirus harboring the focal adhesion kinase shRNA. Int J Oncol. 2015; 47:668-678.

49. Crompton AM, Kirn DH. From ONYX-015 to armed vaccinia viruses: the education and evolution of oncolytic virus development. Curr Cancer Drug Targets. 2007; 7:133139.

50. Nguyen TL, Wilson MG, Hiscott J. Oncolytic viruses and histone deacetylase inhibitors--a multi-pronged strategy to target tumor cells. Cytokine Growth Factor Rev. 2010; 21:153-159.

51. Fujiwara T, Kagawa S, Tazawa H. Synergistic interaction of telomerase-specific oncolytic virotherapy and chemotherapeutic agents for human cancer. Curr Pharm Biotechnol. 2012; 13:1809-1816.

52. Jiang H, Gomez-Manzano C, Lang FF, Alemany R, Fueyo J. Oncolytic adenovirus: preclinical and clinical studies in patients with human malignant gliomas. Curr Gene Ther. 2009; 9:422-427.

53. Yang Z, Zhang Q, Xu K, Shan J, Shen J, Liu L, Xu Y, Xia F, Bie P, Zhang X, Cui Y, Bian XW, Qian C. Combined therapy with cytokine-induced killer cells and oncolytic adenovirus expressing IL-12 induce enhanced antitumor activity in liver tumor model. PLoS One. 2012; 7:e44802.

54. Zhang SN, Choi IK, Huang JH, Yoo JY, Choi KJ, Yun CO. Optimizing DC vaccination by combination with oncolytic adenovirus coexpressing IL-12 and GM-CSF. Mol Ther. 2011; 19:1558-1568.

55. Mao CY, Hua HJ, Chen P, Yu DC, Cao J, Teng LS. Combined use of chemotherapeutics and oncolytic adenovirus in treatment of AFP-expressing hepatocellular carcinoma. Hepatobiliary Pancreat Dis Int. 2009; 8:282287.

56. Zhang J, Ramesh N, Chen Y, Li Y, Dilley J, Working P, Yu DC. Identification of human uroplakin II promoter and its use in the construction of CG8840, a urothelium-specific adenovirus variant that eliminates established bladder tumors in combination with docetaxel. Cancer Res. 2002; 62:3743-3750.

57. Augello C, Caruso L, Maggioni M, Donadon M, Montorsi M, Santambrogio R, Torzilli G, Vaira V, Pellegrini C, Roncalli M, Coggi G, Bosari S. Inhibitors of apoptosis proteins (IAPs) expression and their prognostic significance in hepatocellular carcinoma. BMC Cancer. 2009; 9:125.

58. Chu L, Gu J, Sun L, Qian Q, Qian C, Liu X. Oncolytic adenovirus-mediated shRNA against Apollon inhibits tumor cell growth and enhances antitumor effect of 5-fluorouracil. Gene Ther. 2008; 15:484-494.

59. Shen W, Tu JK, Wang XH, Fu ZX. Oncolytic adenovirus mediated Survivin RNA interference and 5-fluorouracil synergistically suppress the lymphatic metastasis of colorectal cancer. Oncol Rep. 2010; 24:1285-1290.

60. Spitz FR, Nguyen D, Skibber JM, Meyn RE, Cristiano RJ, Roth JA. Adenoviral-mediated wild-type p53 gene expression sensitizes colorectal cancer cells to ionizing radiation. Clin Cancer Res. 1996; 2:1665-1671.

61. Wakasa T, Inoue T, Kawai N, Murakami J, Kishi K, Fukui $\mathrm{K}$. The combination of ionizing radiation and expression of a wild type $\mathrm{p} 53$ gene via recombinant adenovirus induced a prominent tumour suppressing effect in human oral squamous cell carcinoma. Br J Radiol. 2002; 75:657-662.

62. Wang W, Xia X, Wang S, Sima N, Li Y, Han Z, Gao Q, Luo A, Li K, Meng L, Zhou J, Wang C, Shen K, Ma D. 
Oncolytic adenovirus armed with human papillomavirus E2 gene in combination with radiation demonstrates synergistic enhancements of antitumor efficacy. Cancer Gene Ther. 2011; 18:825-836.

63. Gallardo D, Drazan KE, McBride WH. Adenovirus-based transfer of wild-type p53 gene increases ovarian tumor radiosensitivity. Cancer Res. 1996; 56:4891-4893.

64. Taneja SS. Re: Prospective randomized phase 2 trial of intensity modulated radiation therapy with or without oncolytic adenovirus-mediated cytotoxic gene therapy in intermediate-risk prostate cancer. J Urol. 2015; 193:847.

65. Kon T, Zhang X, Huang Q, Yang Z, Liu S, Yan B, Li $\mathrm{F}$, Wang $\mathrm{H}$, Li CY. Oncolytic virus-mediated tumor radiosensitization in mice through DNA-PKcs-specific shRNA. Transl Cancer Res. 2012; 1:4-14.

66. Darcy PK, Neeson P, Yong CS, Kershaw MH. Manipulating immune cells for adoptive immunotherapy of cancer. Curr Opin Immunol. 2014; 27:46-52.

67. Rosenberg SA, Restifo NP, Yang JC, Morgan RA, Dudley ME. Adoptive cell transfer: a clinical path to effective cancer immunotherapy. Nat Rev Cancer. 2008; 8:299-308.

68. Rosenberg SA. Cell transfer immunotherapy for metastatic solid cancer--what clinicians need to know. Nat Rev Clin Oncol. 2011; 8:577-585.

69. Tanimoto T, Hori A, Kami M. Sipuleucel-T immunotherapy for castration-resistant prostate cancer. N Engl J Med. 2010; 363:1966; author reply 1967-1968.

70. Palmer DH, Midgley RS, Mirza N, Torr EE, Ahmed F, Steele JC, Steven NM, Kerr DJ, Young LS, Adams DH. A phase II study of adoptive immunotherapy using dendritic cells pulsed with tumor lysate in patients with hepatocellular carcinoma. Hepatology. 2009; 49:124-132.

71. Gabrilovich D. Mechanisms and functional significance of tumour-induced dendritic-cell defects. Nat Rev Immunol. 2004; 4:941-952.

72. Huang JH, Zhang SN, Choi KJ, Choi IK, Kim JH, Lee MG, Kim H, Yun CO. Therapeutic and tumor-specific immunity induced by combination of dendritic cells and oncolytic adenovirus expressing IL-12 and 4-1BBL. Mol Ther. 2010; 18:264-274.

73. Zacharatos P, Kotsinas A, Evangelou K, Karakaidos P, Vassiliou LV, Rezaei N, Kyroudi A, Kittas C, Patsouris E, Papavassiliou AG, Gorgoulis VG. Distinct expression patterns of the transcription factor E2F-1 in relation to tumour growth parameters in common human carcinomas. J Pathol. 2004; 203:744-753.

74. Yan Y, Xu Y, Zhao Y, Li L, Sun P, Liu H, Fan Q, Liang K, Liang W, Sun H, Du X, Li R. Combination of E2F-1 promoter-regulated oncolytic adenovirus and cytokineinduced killer cells enhances the antitumor effects in an orthotopic rectal cancer model. Tumour Biol. 2014; 35:1113-1122.

75. Yan Y, Li S, Jia T, Du X, Xu Y, Zhao Y, Li L, Liang K, Liang W, Sun H, Li R. Combined therapy with CTL cells and oncolytic adenovirus expressing IL-15-induced enhanced antitumor activity. Tumour Biol. 2015; 36:45354543.

76. Tobias A, Ahmed A, Moon KS, Lesniak MS. The art of gene therapy for glioma: a review of the challenging road to the bedside. J Neurol Neurosurg Psychiatry. 2013; 84:213222.

77. Pierce GB. Teratocarcinoma: model for a developmental concept of cancer. Curr Top Dev Biol. 1967; 2:223-246.

78. Singh SK, Hawkins C, Clarke ID, Squire JA, Bayani J, Hide T, Henkelman RM, Cusimano MD, Dirks PB. Identification of human brain tumour initiating cells. Nature. 2004; 432:396-401.

79. Nandi S, Ulasov IV, Tyler MA, Sugihara AQ, Molinero L, Han Y, Zhu ZB, Lesniak MS. Low-dose radiation enhances survivin-mediated virotherapy against malignant glioma stem cells. Cancer Res. 2008; 68:5778-5784.

80. Eramo A, Lotti F, Sette G, Pilozzi E, Biffoni M, Di Virgilio A, Conticello C, Ruco L, Peschle C, De Maria R. Identification and expansion of the tumorigenic lung cancer stem cell population. Cell Death Differ. 2008; 15:504-514.

81. Prince ME, Sivanandan R, Kaczorowski A, Wolf GT, Kaplan MJ, Dalerba P, Weissman IL, Clarke MF, Ailles LE. Identification of a subpopulation of cells with cancer stem cell properties in head and neck squamous cell carcinoma. Proc Natl Acad Sci U S A. 2007; 104:973-978.

82. Friedman GK, Gillespie GY. Cancer Stem Cells and Pediatric Solid Tumors. Cancers (Basel). 2011; 3:298-318.

83. Takenobu H, Shimozato O, Nakamura T, Ochiai $\mathrm{H}$, Yamaguchi Y, Ohira M, Nakagawara A, Kamijo T. CD133 suppresses neuroblastoma cell differentiation via signal pathway modification. Oncogene. 2011; 30:97-105.

84. Ranki T, Kanerva A, Ristimaki A, Hakkarainen T, Sarkioja M, Kangasniemi L, Raki M, Laakkonen P, Goodison S, Hemminki A. A heparan sulfate-targeted conditionally replicative adenovirus, Ad5.pk7-Delta24, for the treatment of advanced breast cancer. Gene Ther. 2007; 14:58-67.

85. Ranki T, Sarkioja M, Hakkarainen T, von Smitten K, Kanerva A, Hemminki A. Systemic efficacy of oncolytic adenoviruses in imagable orthotopic models of hormone refractory metastatic breast cancer. Int J Cancer. 2007; 121:165-174.

86. Eriksson M, Guse K, Bauerschmitz G, Virkkunen P, Tarkkanen M, Tanner M, Hakkarainen T, Kanerva A, Desmond RA, Pesonen S, Hemminki A. Oncolytic adenoviruses kill breast cancer initiating CD44+CD24-/low cells. Mol Ther. 2007; 15:2088-2093.

87. Lamfers ML, Grill J, Dirven CM, Van Beusechem VW, Geoerger B, Van Den Berg J, Alemany R, Fueyo J, Curiel DT, Vassal G, Pinedo HM, Vandertop WP, Gerritsen WR. Potential of the conditionally replicative adenovirus Ad5Delta24RGD in the treatment of malignant gliomas and its enhanced effect with radiotherapy. Cancer Res. 2002; 62:5736-5742. 
88. Lang FF, Conrad C, Gomez-Manzano C, Tufaro F, Yung W, Sawaya R, Weinberg J, Prabhu S, Fuller G, Aldape K, Fueyo J. First-in-Human Phase I Clinical Trial of Oncolytic Delta-24-Rgd (Dnx-2401) with Biological Endpoints: Implications for Viro- Immunotherapy. Neuro-Oncology. 2014; 16:iii39-iii39.

89. Berghauser Pont LM, Kleijn A, Kloezeman JJ, van den Bossche W, Kaufmann JK, de Vrij J, Leenstra S, Dirven CM, Lamfers ML. The HDAC Inhibitors Scriptaid and LBH589 Combined with the Oncolytic Virus Delta24-RGD Exert Enhanced Anti-Tumor Efficacy in Patient-Derived Glioblastoma Cells. PLoS One. 2015; 10:e127058.

90. Bauerschmitz GJ, Ranki T, Kangasniemi L, Ribacka C, Eriksson M, Porten M, Herrmann I, Ristimaki A, Virkkunen P, Tarkkanen M, Hakkarainen T, Kanerva A, Rein D, Pesonen S, Hemminki A. Tissue-specific promoters active in CD44+CD24-/low breast cancer cells. Cancer Res. 2008; 68:5533-5539.

91. Russell SJ, Peng KW, Bell JC. Oncolytic virotherapy. Nat Biotechnol. 2012; 30:658-670.

92. Reagan MR, Kaplan DL. Concise review: Mesenchymal stem cell tumor-homing: detection methods in disease model systems. Stem Cells. 2011; 29:920-927.

93. Komarova S, Kawakami Y, Stoff-Khalili MA, Curiel DT, Pereboeva L. Mesenchymal progenitor cells as cellular vehicles for delivery of oncolytic adenoviruses. Molecular Cancer Therapeutics. 2006; 5:755-766.
94. Stoff-Khalili MA, Rivera AA, Mathis JM, Banerjee NS, Moon AS, Hess A, Rocconi RP, Numnum TM, Everts M, Chow LT, Douglas JT, Siegal GP, Zhu ZB, Bender HG, Dall P, Stoff A, Pereboeva L, Curiel DT. Mesenchymal stem cells as a vehicle for targeted delivery of CRAds to lung metastases of breast carcinoma. Breast Cancer Research and Treatment. 2007; 105:157-167.

95. Sonabend AM, Ulasov IV, Tyler MA, Rivera AA, Mathis JM, Lesniak MS. Mesenchymal stem cells effectively deliver an oncolytic adenovirus to intracranial glioma. Stem Cells. 2008; 26:831-841.

96. Josiah DT, Zhu D, Dreher F, Olson J, McFadden G, Caldas H. Adipose-derived stem cells as therapeutic delivery vehicles of an oncolytic virus for glioblastoma. Mol Ther. 2010; 18:377-385.

97. Yong RL, Shinojima N, Fueyo J, Gumin J, Vecil GG, Marini FC, Bogler O, Andreeff M, Lang FF. Human bone marrow-derived mesenchymal stem cells for intravascular delivery of oncolytic adenovirus Delta24-RGD to human gliomas. Cancer Res. 2009; 69:8932-8940.

98. Hammer K, Kazcorowski A, Liu L, Behr M, Schemmer P, Herr I, Nettelbeck DM. Engineered adenoviruses combine enhanced oncolysis with improved virus production by mesenchymal stromal carrier cells. Int J Cancer. 2015; 137:978-990. 